\title{
Teaching competition in professional sports leagues
}

\author{
Stefan Szymanski ${ }^{1}$
}

May 2006

\begin{abstract}
In recent years there has been some dispute over the appropriate way to model decisionmaking in professional sports leagues. In particular, Szymanski and Kesenne (2004), argue that formulating the decision-making problem as a noncooperative game leads to radically different conclusions about the nature of competition in sports leagues. This paper describes a simulation model that van be used in a classroom to demonstrate how competition works in a noncooperative context. The supporting Excel spreadsheet used to conduct the game can be downloaded from the author's personal webpage http://www3.imperial.ac.uk/people/s.szymanski
\end{abstract}

JEL Classification Codes: A20, D43, L83

Keywords: sports, teaching methods

* Paper presented at the Joint Annual Meeting 2006 of the International and German-Speaking Associations of Sports Economists (IASE and AK), May 4-6, 2006

${ }^{1}$ Stefan Szymanski, Tanaka Business School, Imperial College London, South Kensington campus, SW7 2AZ, UK. Tel : (44) 207594 9107, Fax: (44) 207823 7685, e-mail: szy@imperial.ac.uk. I would like to thank students at the University of Antwerp and the University of Zurich for their contribution to trying out the simulation game described in this paper. 


\section{Introduction}

Formal mathematical modelling of sports leagues began with the work of El-Hodiri and Quirk (1971). Such models typically assume that team owners make choices about investment in talent, that talent generates wins in the league and that in turn wins generate revenues. Predictions are associated with the equilibrium distribution of wins either in a profit maximising model (e.g. Atkinson et all (1988), Fort and Quirk (1995), Vrooman (1995), Marburger (1997)) or a win maximising model (e.g. Kesenne (1996, 2000)). The purpose of this modelling has been to make predictions about the impact of policy measures such as gate revenue sharing on quantities such as league-wide profits and competitive balance.

In recent years there has been a technical debate in the literature about the way in which the model is constructed. Essentially, models that follow in the tradition of ElHodiri and Quirk are based on two sets of assumptions

(a) each team owner chooses a quantity of talent to hire in the market, and this quantity translates one-for-one into a quantity of wins in the league

(b) equilibrium is identified as the point where marginal benefits are equalised across teams (in the profit maximising model this means the point where the marginal revenue of a win is equalised, in the win maximisation model it means the point where the average revenue of a win is equalised).

Szymanski (2003, 2004a) and Szymanski and Kesenne (2004) take issue with the first of these assumptions on both theoretical and practical grounds. In terms of the theory, they argue that there is no coherent game theoretic interpretation of the assumption that talent has a one-to-one correspondence with wins, since this implies that each team is capable of choosing wins independently of the other teams. Logically, the wins of one team in a league must depend on the talent choices of the other teams as well. More practically, they argue that teams do not in fact choose wins unless they are engaged in match fixing. In practice, teams allocate a budget to the hiring of talent in the market, with the result that each team's share of talent in the market is roughly proportional to its share of aggregate team budgets. They also show that modelling the 
choice of budgets as a non-cooperative games generates predictions that are dramatically different from the conventional results in the literature.

Some critics view this debate as a rather abstract dispute over modelling assumptions with little or no practical consequence. Moreover, the fact the models are usually framed using very simple assumptions, most notoriously the "two-team league" assumption, others have questioned the practical relevance of the issue.

This paper aims to illustrate the practical relevance of the debate by presenting a version of the game theoretic model that can be used for the purposes of classroom simulation of a sports league. Engaging students in a simulation brings to life the constraints faced by owners and managers in the decision making process. It can also help to provide insights into the effectiveness of the types of mechanisms that have been designed to alleviate some of the consequences of economic competition between teams in a league. The paper provides a full description of the model so that the reader can run the simulation model for themselves, and to aid the use of the model a spreadsheet version can be downloaded from the author's personal web page. $^{2}$ The details of this spreadsheet are also explained in the paper.

The paper proceeds as follows. In the next section the basic assumptions behind the model are explained and the way the simulation can be run in class is discussed. The following describes the simulation model and assumptions behind it. Section 3 presents the mathematical model on which the simulation is based and the derivation of the Nash equilibrium under profit maximisation and the joint profit maximising solution. Section 4 presents the results of some simulations run with students at the University of Antwerp and the University of Zurich. Details of the spreadsheet are provided in the appendices.

\footnotetext{
${ }^{2}$ http://www3.imperial.ac.uk/people/s.szymanski
} 


\section{The assumptions in the simulation model}

The simulation model relates economic inputs to sporting and economic outputs. In the model teams hire talent which then produces wins, and wins in turn generates profit, which is the difference between the cost of talent and the revenue generated by wins. Thus there are two key economic relationships that must be specified:

(a) the relationship between expenditure and success on the playing field

(b) the relationship between success on the playing field and revenues

These relationships are defined by a set of parameters which characterise the league competition in question. The simulation model in this paper is based on empirical estimates of these relationships for the American League, one half of Major League Baseball, for the year 2003. However, it is quite easy, once the model is understood, to develop a model of any league, either using parameters estimated from empirical data or based on "guesstimates".

\section{(a) Expenditure and winning}

Few would argue against the proposition that teams which spend more on average win more on average. A bigger budget for player spending means better players can be hired. Because there is a market for playing talent, expenditure is correlated with expected success, and actual success is correlated with expected success. Neither of these relationships is perfect: sometimes managers make bad choices, and sometimes players do not perform as expected (especially when they are injured).

The degree of sensitivity of winning to spending is captured by the Tullock contest success function

$$
w_{i}=\frac{n}{2} \frac{B_{i}^{\gamma}}{\sum_{j=1}^{n} B_{j}^{\gamma}}
$$


Here $\mathrm{w}_{\mathrm{i}}$ represents the percentage of games played by team $\mathrm{i}$ that it wins. If ties (draws) are permitted, the each one is treated as half of a win. If there are $\mathrm{n}$ teams in the league the total win percentages sum to $\mathrm{n} / 2$ (e.g. if there are 14 teams, as in the American League, then the total percentages won sum to 7 or $700 \%)$. Given this total to be shared out, equation (1) says that they will be allocated in relation to team budgets B, and each team's share of wins is proportional to its share in total team budgets. The degree of sensitivity in this relationship is measured by the parameter $\gamma$. If $\gamma$ is very large, then small differences in the $\mathrm{B}_{\mathrm{i}}$ 's translate into large differences in team performance. If $\gamma$ equalled zero then spending would make no difference to performance.

To illustrate the impact of spending for different values of $\gamma$, table 1 shows the expected win percentage of a team for a given level of expenditure by other teams in a 14 team league.

\section{Table 1: Expected win percentages for different levels of expenditure assuming a} 14 team league in which the other teams each spend 100

$\begin{array}{llll}\text { budget } & \gamma=\mathbf{1} & \gamma=\mathbf{0 . 5} & \gamma=\mathbf{0 . 2 5} \\ \mathbf{0} & 0.000 & 0.000 & 0.000 \\ \mathbf{2 5} & 0.132 & 0.259 & 0.361 \\ \mathbf{5 0} & 0.259 & 0.361 & 0.425 \\ \mathbf{7 5} & 0.382 & 0.437 & 0.468 \\ \mathbf{1 0 0} & 0.500 & 0.500 & 0.500 \\ \mathbf{1 2 5} & 0.614 & 0.554 & 0.527 \\ \mathbf{1 5 0} & 0.724 & 0.603 & 0.549 \\ \mathbf{1 7 5} & 0.831 & 0.647 & 0.569 \\ \mathbf{2 0 0} & 0.933 & 0.687 & 0.587 \\ \mathbf{2 2 5} & 1.033 & 0.724 & 0.603\end{array}$

Note that expected win percentage exceeds the maximum feasible $100 \%$ if the budget exceeds a critical level. Therefore in the simulation model we introduce an extra constraint- if team i's budget is such that the value taken by equation (1) would be greater than unity, the team's actual win percentage is constrained to equal unity (100\% wins). 


\section{(b) Winning and revenues}

The relationship between winning and revenues can be estimated for any given league using historical data. Winning increases revenues because the majority of those who attend league games support the home team. Home team fans want to see their team win. There are a number of factors that are known to increase revenues. In the American League it has been shown that the construction of a new ballpark increases attendance, while other factors such as past success contribute to wins. The assumed relationship between attendance and winning in this model thus takes the form

(2) Attendance $e_{i}=a_{i}+b_{i} w_{i}+c_{i} w_{i}^{2}$

The derivation of these coefficients for the American League is explained in the appendix. The estimated coefficients, a, b and c for each team are given in Table 2.

Table 2: Estimated parameters for the sensitivity of attendance to wins for the American League

$\begin{array}{lccc}\text { Name } & \text { a } & \text { b } & \text { c } \\ \text { Anaheim Angels } & 1636393 & 2286830 & -821530 \\ \text { Baltimore Orioles } & 40217 & 9250152 & -6321152 \\ \text { Boston Red Sox } & 721947 & 5382117 & -3415917 \\ \text { Chicago White Sox } & 187050 & 3517734 & -1214034 \\ \text { Cleveland Indians } & -632951 & 10950601 & -7713601 \\ \text { Detroit Tigers } & -389802 & 7366947 & -4508447 \\ \text { Kansas City Royals } & -259625 & 4852119 & -2114319 \\ \text { Minnesota Twins } & -1539935 & 8070813 & -3347513 \\ \text { New York Yankees } & 1045703 & 5045135 & -1895735 \\ \text { Oakland Athletics } & -145096 & 5025231 & -1950831 \\ \text { Seattle Mariners } & 1543096 & 5363387 & -3090087 \\ \text { Tampa Bay Devil Rays } & 207550 & 2320631 & -523431 \\ \text { Texas Rangers } & 1319440 & 2970135 & -1499935 \\ \text { Toronto Blue Jays } & 284278 & 3094233 & -923433\end{array}$




\section{(c) Playing the Game}

Given the parameters of the model the game can now be run on spreadsheet. In order to play the game it is useful to provide an instruction sheet (see appendix 1). The instruction sheet should explain the relationships above and then participants should be invited to choose or allocated a team.

The game is essentially a one-shot game. Each team chooses a budget which, for example, they can write down on a decision slip (see appendix 2). Each team does so independently and then hands the slip to the instructor. Once they have all been collected the instructor inputs the decisions onto the spreadsheet, and the combination of individual decisions then determines the win percentage, revenue and profit of each team.

The game is best played several times over, in order that students can learn from the experiences of earlier rounds. However, it is very important to emphasise to participants that the game is one-shot, so that choices made in past rounds do not directly affect current decisions, and current decisions have no long term consequences (at least directly). It is important to note, however, that teams learn about behaviour from previous rounds and that therefore there are some indirect effects; indeed, in a sense, this is the whole point of the simulation. ${ }^{3}$

Given that we have a relationship between spending and winning (equation 1) and between winning and attendance (equation 2), we can calculate the consequences of different budget choices made by individual teams. Each team can choose its own budget, but the number of wins for each team will depend not only on their own budget, but on the budget of every other team. The winning percentage for each team then determines attendance. ${ }^{4}$ The revenue depends on both attendance and prices. In the American League model we assume that each team generates $\$ 60$ of income per

\footnotetext{
${ }^{3}$ It would be possible without too much manipulation to make the game dynamic, but this would then make it difficult or impossible to identify an equilibrium of the game, and students might learn little more than the trite observation that "anything can happen".

${ }^{4}$ Although if spending is low enough, the negative coefficient "a” for some teams implies negative attendance. This is ruled out in the spreadsheet by requiring attendance to be non-negative.
} 
fan, but in fact the value can be changed in the spreadsheets so that it can be allowed to vary for each team. Thus the profit for team i, given equations (1) and (2), is

(3) $\quad \pi_{\mathrm{i}}=\mathrm{p}_{\mathrm{i}}\left(\mathrm{a}_{\mathrm{i}}+\mathrm{b}_{\mathrm{i}} \mathrm{w}_{\mathrm{i}}+\mathrm{c}_{\mathrm{i}} \mathrm{w}_{\mathrm{i}}^{2}\right)-\mathrm{B}_{\mathrm{i}}$

Where $p_{i}$ is the expected revenue per fan.

It will be noted that so far nothing has been set about objectives. Typically American economists have assumed profit maximising behaviour and European economists have assumed win maximising behaviour. These assumptions produce different theoretical results. However, in the simulation it is up to the instructor to decide how to direct the participants. It may in practice be easier to demonstrate the nature of the model by asking participants to act as profit maximisers, since there is then a clear benchmark for success in game. Indeed, in a classroom situation one might even award grades for the level of profits generated. The analogy in a win maximising model is that a player of the game is maximally successful if they achieve a budget exactly equal to zero, and the closer they are to zero, the greater their success. However, it might be argued that there should be asymmetric penalties for over and under-spending (since the consequences of overspending are likely to be more severe). All this is in the gift of the instructor- the simulation model is consistent with any combination of profit maximising and win maximising behaviour.

Before discussing some of the experiences of classes that have played the game, it is useful to characterise the Nash equilibrium of the game.

\section{Nash equilibrium and optimality}

Given the assumed objectives of the players, there will in general exist an interior Nash equilibrium of the model. Given the choices of every other team, each team possesses a "best response"- a choice of budgetary expenditure that maximises each team's objective function. If every team's budget decision were simultaneously a best 
response, then the budgets would constitute a "Nash equilibrium”. At a Nash equilibrium no team would wish to alter its choice.

The Nash equilibrium is not necessary optimal from the point of view of the league. If we were to take the perspective of the league as a whole, imagining it was a cartel whose objective was to share out the wins in such a way as to generate the maximum possible attendance (and therefore revenue), we would need to identify the point where the marginal revenue (MR) of a win was equal for every team. To see why this is so, imagine that for a given set of win percentages one team had a higher marginal revenue than another. In such a case it would be possible to increase total revenue by taking one win away from the low MR team and giving it to the high MR team- the gain would outweigh the loss. If all MR's are equal, however, it is not possible to redistribute wins to increase total revenues. Notice that this optimality condition is independent of the budgets of the teams- these do not play a role in determining the optimal distribution of wins.

\section{(a) Deriving the Nash equilibrium}

Given (1), (2) and (3) the first order condition for profit to be a maximum is thus

$$
\frac{\partial \pi_{i}}{\partial B_{i}}=p_{i}\left(b_{i}+2 c_{i} w_{i}\right) \frac{\partial w_{i}}{\partial B_{i}}-1=0
$$

where

$$
\frac{\partial w_{i}}{\partial B_{i}}=\frac{n}{2}\left(\frac{\sum_{j=1}^{n} B_{j}^{\gamma} \gamma B_{i}^{\gamma-1}-B_{i}^{\gamma} \gamma B_{i}^{\gamma-1}}{\left(\sum_{j=1}^{n} B_{j}^{\gamma}\right)^{2}}\right)=\left(\frac{n}{2}\right)^{-1} \frac{\gamma}{B_{i}} w_{i}\left(\frac{n}{2}-w_{i}\right)
$$

so that we can rewrite (4) as 
(6) $\quad \gamma\left(\frac{n}{2}\right)^{-1} p_{i}\left(b_{i}+2 c_{i} w_{i}\right) w_{i}\left(\frac{n}{2}-w_{i}\right)=B_{i}$

However, we can also define the individual budget $\mathrm{B}_{\mathrm{i}}$ of a team in terms of the sum of budgets of all teams, using (1):

$$
B_{i}=\left(\frac{n}{2}\right)^{-\frac{1}{\gamma}} w^{\frac{1}{\gamma}}\left(\sum_{j=1}^{n} B_{j}^{\gamma}\right)^{\frac{1}{\gamma}}
$$

and thus (6) can be rewritten as the equilibrium condition

$$
\gamma\left(\frac{n}{2}\right)^{\frac{1-\gamma}{\gamma}} p_{i}\left(b_{i}+2 c_{i} w_{i}\right) w_{i}^{\frac{\gamma-1}{\gamma}}\left(\frac{n}{2}-w_{i}\right)=\left(\sum_{j=1}^{n} B_{i}^{\gamma}\right)^{\frac{1}{\gamma}}
$$

Note that the RHS of (8) is common to all teams. Another way to rewrite the equilibrium condition therefore is

$$
p_{i}\left(b_{i}+2 c_{i} w_{i}\right) w_{i}^{\frac{\gamma-1}{\gamma}}\left(\frac{n}{2}-w_{i}\right)=p_{j}\left(b_{j}+2 c_{j} w_{j}\right) w_{j}^{\frac{\gamma-1}{\gamma}}\left(\frac{n}{2}-w_{j}\right)
$$

for every team i and j. It is straightforward to solve this system of equations numerically if the parameters b, c, p and $\gamma$ are known. "b" and "c" can be recovered by regressing attendance on win percentage, the value of "p", which is essentially revenue per fan, can be derived directly from income statements of the clubs, while $\gamma$ can be derived from the relationship between win percentage and team player budgets (appendix 5 describes how this can be done on an Excel spreadsheet). 
It is useful to consider the values that this condition takes for different values of $\gamma$ :

$$
\begin{array}{ll}
\gamma=1: & p_{i}\left(b_{i}+2 c_{i} w_{i}\right)\left(\frac{n}{2}-w_{i}\right) \\
\gamma=\frac{1}{2}: & p_{i}\left(b_{i}+2 c_{i} w_{i}\right) w_{i}^{-1}\left(\frac{n}{2}-w_{i}\right) \\
\gamma=\frac{1}{3}: & p_{i}\left(b_{i}+2 c_{i} w_{i}\right) w_{i}^{-2}\left(\frac{n}{2}-w_{i}\right) \\
\gamma=\frac{1}{4}: & p_{i}\left(b_{i}+2 c_{i} w_{i}\right) w_{i}^{-3}\left(\frac{n}{2}-w_{i}\right)
\end{array}
$$

\section{(b) The optimum for the league cartel}

We now compare this with the condition for league revenues as a whole to be maximised. This requires the marginal revenue of a win to be equalised across teams, regardless of budgets. The condition is given by the derivative of (2) with respect to winning percentage and hence:

$$
p_{i}\left(b_{i}+2 c_{i} w_{i}\right)=p_{j}\left(b_{j}+2 c_{j} w_{j}\right)
$$

We can solve explicitly for $\mathrm{w}_{\mathrm{j}}$ as follows. First, from (11)

$$
w_{i}=\frac{p_{j} b_{j}-p_{i} b_{i}}{2 p_{i} c_{i}}+\frac{p_{j} c_{j}}{p_{i} c_{i}} w_{j}
$$

If we sum over all $w_{\mathrm{i}}$ not including $\mathrm{w}_{\mathrm{j}}$, then

$$
\sum_{i \neq j} w_{i}=\sum_{i \neq j}\left(\frac{p_{j} b_{j}-p_{i} b_{i}}{2 p_{i} c_{i}}\right)+p_{j} c_{j} w_{j} \sum_{i \neq j} \frac{1}{p_{i} c_{i}}
$$

but also

$$
\sum_{(i \neq j)} w_{i}=n / 2-w_{j} .
$$


(this is the adding up constraint introduced in (1)), and hence

$$
w_{j}^{*}=\frac{\frac{n}{2}-\sum_{i \neq j}\left(\frac{p_{j} b_{j}-p_{i} b_{i}}{2 p_{i} c_{i}}\right)}{1+p_{j} c_{j} \sum_{i \neq j} \frac{1}{p_{i} c_{i}}}
$$

The solution in (15) defines the distribution of win percentages that maximises total revenues. A planner interested in maximising total revenue would therefore distribute playing talent in such a way as to produce these win percentages. In theory there is no need for the planner to use the market mechanism, i.e. playing budgets. However, it is possible to identify the budget distribution that would generate the optimal win percentages by using (7). For any team the budget must be proportional to

$$
B_{i}^{*}=K\left(\frac{n}{2}\right)^{-\frac{1}{\gamma}}\left(w_{i}^{*}\right)^{\frac{1}{\gamma}}
$$

Where $\mathrm{K}$ is a constant that can be adjusted to define the total player budget. Of course, given that only the relative size of the budgets matter for allocating talent, it would be possible for the planner to reduce total expenditure to the level of the players’ reservation wage.

\section{The classroom experience}

The game has been played by students taking a sports economics class at the University of Antwerp and the University of Zurich. Below is described the experience of one group. Each team was represented by a single student.

Before making their first decision, the teams were told that the data represented roughly the situation in which the American League found itself in 2003, and that in fact the teams had spent about $\$ 1.2$ billion on player salaries. After allowing about five minutes to understand the problem (and answering questions of clarification), the students were required to submit their budget slips. When each team is represented by 
a group of students somewhat more discussion time is required. The budget choices were then entered into the spreadsheet, and when this was done the outcome was then shown on a projector. This appeared as in figure 1.

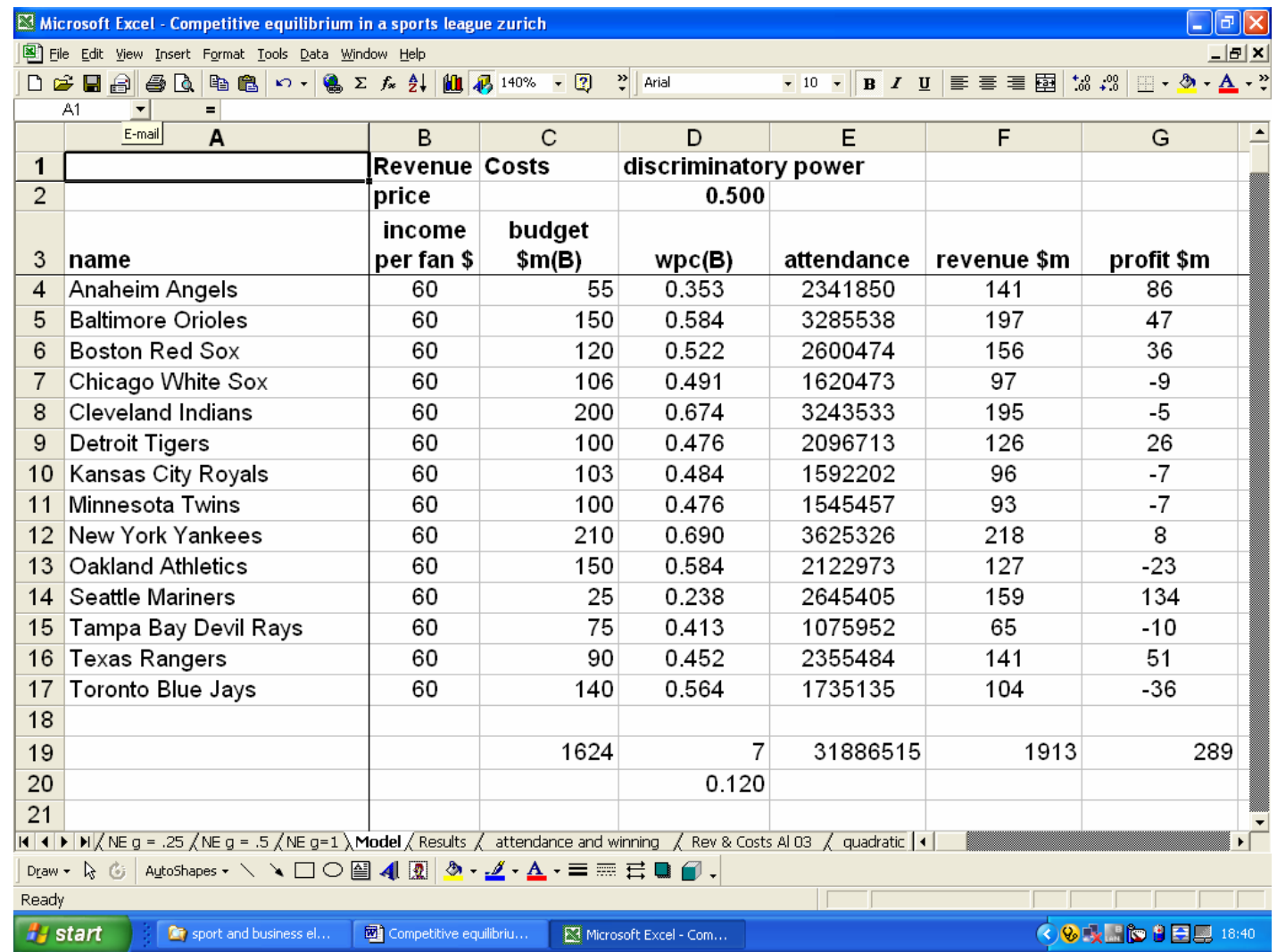

Figure 1: Screen for round 1 of the game

The aggregate spending in the first round was very high- about $30 \%$ higher than the actual spending. The range varied from \$25 million to \$210 million. Given that the students were supposed to be acting as profit maximisers, those who made losses were asked to comment. Most quickly saw that reducing expenditure would increase profits. Students could see quite easily that some teams started with a stronger supporter base, but that what really mattered in terms of the budget choice was 
whether the team had a large sensitivity of revenues to wins, captured in the " $\mathrm{b}$ " and “c” parameters. We then moved to round 2, the results of which are shown in table 3.

Table 3: Round 2 of the game

\begin{tabular}{lrrrrr}
\multicolumn{7}{c}{ Round 2 } & \multicolumn{7}{c}{ Name } & budget \$m(B) wpc(B) & \multicolumn{3}{c}{ attendance Revenue \$m profit \$m } \\
Anaheim Angels & 35 & 0.376 & 2380244 & 143 & 108 \\
Baltimore Orioles & 150 & 0.779 & 3410403 & 205 & 55 \\
Boston Red Sox & 115 & 0.682 & 2803522 & 168 & 53 \\
Chicago White Sox & 40 & 0.402 & 1405128 & 84 & 44 \\
Cleveland Indians & 100 & 0.636 & 3211174 & 193 & 93 \\
Detroit Tigers & 20 & 0.284 & 1340201 & 80 & 60 \\
Kansas City Royals & 50 & 0.450 & 1494238 & 90 & 40 \\
Minnesota Twins & 50 & 0.450 & 1411589 & 85 & 35 \\
New York Yankees & 180 & 0.853 & 3969648 & 238 & 58 \\
Oakland Athletics & 80 & 0.569 & 2081514 & 125 & 45 \\
Seattle Mariners & 18 & 0.270 & 2764861 & 166 & 148 \\
Tampa Bay Devil Rays & 40 & 0.402 & 1055961 & 63 & 23 \\
Texas Rangers & 90 & 0.603 & 2565138 & 154 & 64 \\
Toronto Blue Jays & 15 & 0.246 & 990124.9 & 59 & 44 \\
& \multicolumn{7}{c}{3083745} & 1853 & 870 \\
Sum & 983 & 0.191 & & &
\end{tabular}

Total spending was nearly halved. Revenues, however, fell only slightly, and therefore profits were three times larger than in the first round. Note that the variance of win percentages also increased, since the few teams that continued to spend at a high level achieved very high win percentages (and relatively low profits). The concept of a best response was now discussed- could each team identify a best response? We then moved to round 3, the results of which are shown in Table 5.

By round 3 every team had recognised the advantage to keeping spending down and aggregate spending was now one third of the level in the first round, and profits were about four times larger. Now students found that changing their decision made very little difference to total profit- most teams were close to their best response. Round 4 (Table 6) illustrated that the group was getting closer to an equilibrium. 
Table 5: Round 3 of the game

\begin{tabular}{|c|c|c|c|c|c|}
\hline \multirow{2}{*}{$\begin{array}{l}\text { Name } \\
\text { Anaheim Angels }\end{array}$} & \multicolumn{5}{|l|}{ Round 3} \\
\hline & 20 & 0.361 & 2355599 & 141 & 121 \\
\hline Baltimore Orioles & 40 & 0.511 & 3116837 & 187 & 147 \\
\hline Boston Red Sox & 60 & 0.626 & 2752548 & 165 & 105 \\
\hline Chicago White Sox & 25 & 0.404 & 1410288 & 85 & 60 \\
\hline Cleveland Indians & 80 & 0.723 & 3252240 & 195 & 115 \\
\hline Detroit Tigers & 15 & 0.313 & 1474388 & 88 & 73 \\
\hline Kansas City Royals & 10 & 0.256 & 842323.2 & 51 & 41 \\
\hline Minnesota Twins & 30 & 0.443 & 1376733 & 83 & 53 \\
\hline New York Yankees & 90 & 0.767 & 3799447 & 228 & 138 \\
\hline Oakland Athletics & 80 & 0.723 & 2468070 & 148 & 68 \\
\hline Seattle Mariners & 12 & 0.280 & 2802438 & 168 & 156 \\
\hline Tampa Bay Devil Rays & 50 & 0.571 & 1362774 & 82 & 32 \\
\hline Texas Rangers & 90 & 0.767 & 2714939 & 163 & 73 \\
\hline Toronto Blue Jays & 10 & 0.256 & 1014750 & 61 & 51 \\
\hline $\begin{array}{l}\text { Sum } \\
\text { standard deviation }\end{array}$ & 612 & 0.196 & 30743373 & 1845 & 1233 \\
\hline
\end{tabular}

Table 6: Round 4 of the game

\begin{tabular}{|c|c|c|c|c|c|}
\hline \multirow{2}{*}{$\begin{array}{l}\text { name } \\
\text { Anaheim Angels }\end{array}$} & \multicolumn{2}{|c|}{$\begin{array}{l}\text { Round } 4 \\
\text { budget } \$ \mathrm{~m}(\mathrm{~B}) \mathrm{wpc}(\mathrm{B})\end{array}$} & \multicolumn{3}{|c|}{ attendance revenue $\$ \mathrm{~m}$ profit $\$ \mathrm{~m}$} \\
\hline & 25 & 0.381 & 2388561 & 143 & 118 \\
\hline Baltimore Orioles & 50 & 0.539 & 3189463 & 191 & 141 \\
\hline Boston Red Sox & 45 & 0.511 & 2580768 & 155 & 110 \\
\hline Chicago White Sox & 30 & 0.417 & 1443983 & 87 & 57 \\
\hline Cleveland Indians & 65 & 0.614 & 3183429 & 191 & 126 \\
\hline Detroit Tigers & 50 & 0.539 & 2271021 & 136 & 86 \\
\hline Kansas City Royals & 30 & 0.417 & 1397464 & 84 & 54 \\
\hline Minnesota Twins & 55 & 0.565 & 1952493 & 117 & 62 \\
\hline New York Yankees & 80 & 0.682 & 3604008 & 216 & 136 \\
\hline Oakland Athletics & 70 & 0.638 & 2266107 & 136 & 66 \\
\hline Seattle Mariners & 13 & 0.275 & 2783622 & 167 & 154 \\
\hline Tampa Bay Devil Rays & 45 & 0.511 & 1257211 & 75 & 30 \\
\hline Texas Rangers & 65 & 0.614 & 2578175 & 155 & 90 \\
\hline Toronto Blue Jays & 15 & 0.295 & 1117191 & 67 & 52 \\
\hline $\begin{array}{l}\text { Sum } \\
\text { standard deviation }\end{array}$ & 638 & 0.126 & 32013496 & 1921 & 1283 \\
\hline
\end{tabular}

In this round the aggregate result was quite similar to the previous round. As a result, although some groups changed their budget quite significantly, it proved harder to 
affect profits significantly. This led naturally to a discussion of the idea that each team might simultaneously be at a best response. Some thought this was possible, others not. At this point the concept of the Nash equilibrium was introduced and the relevant values shown on the spreadsheet. As a final stage in the exercise the, distribution of wins which maximises total attendance was examined, this being different from the competitive Nash equilibrium. 


\section{Appendix 1: Instructions for participants in the American League game.}

(NB the spreadsheet for the game can be downloaded at http://www3.imperial.ac.uk/people/s.szymanski)

Imagine you are the owner of a team in the American League and that your sole objective is to maximise profits. Profits equal revenues minus costs. Costs equal the budget devoted to hiring playing talent. Revenue depends on the percentage of games won, which can range between zero and $100 \%$. The exact relationships depend on the following two equations:

$$
w_{i}=\frac{n}{2} \frac{B_{i}^{\gamma}}{\sum_{j=1}^{n} B_{j}^{\gamma}}
$$

(The pay-performance relationship)

$$
\text { Attendance }_{\mathrm{i}}=\mathrm{a}_{\mathrm{i}}+\mathrm{b}_{\mathrm{i}} \mathrm{w}_{\mathrm{i}}+\mathrm{c}_{\mathrm{i}} \mathrm{w}_{\mathrm{i}}^{2} \quad \text { (The attendance-win relationship) }
$$

\section{The pay-performance relationship}

Here $\mathrm{w}_{\mathrm{i}}$ represents the percentage of games played by team $\mathrm{i}$ that it wins. For $\mathrm{n}$ teams in the league the total win percentages sum to $n / 2$. In the American League there are 14 teams and so the total percentages won sum to 7 (700\%). B is the team budgets and each team's share of wins is proportional to its share in total team budgets. The degree of sensitivity in this relationship is measured by the parameter $\gamma$. If $\gamma$ is very large, then small differences in $\gamma$ translate into large differences in team performance. If $\gamma$ equalled zero then spending would make no difference to performance. To illustrate the impact of spending for different values of $\gamma$, table 1 shows the expected win percentage of a team for a given level of expenditure by other teams in a 14 team league.

Table 1: Expected win percentages for different levels of expenditure assuming a 14 team league in which the other teams each spend 100

$\begin{array}{llll}\text { budget } & \gamma=\mathbf{1} & \gamma=\mathbf{0 . 5} & \gamma=\mathbf{0 . 2 5} \\ \mathbf{0} & 0.000 & 0.000 & 0.000 \\ \mathbf{2 5} & 0.132 & 0.259 & 0.361 \\ \mathbf{5 0} & 0.259 & 0.361 & 0.425 \\ \mathbf{7 5} & 0.382 & 0.437 & 0.468 \\ \mathbf{1 0 0} & 0.500 & 0.500 & 0.500 \\ \mathbf{1 2 5} & 0.614 & 0.554 & 0.527 \\ \mathbf{1 5 0} & 0.724 & 0.603 & 0.549 \\ \mathbf{1 7 5} & 0.831 & 0.647 & 0.569 \\ \mathbf{2 0 0} & 0.933 & 0.687 & 0.587 \\ \mathbf{2 2 5} & 1.033 & 0.724 & 0.603\end{array}$

In the game a value of $\gamma=0.5$ will be assumed. 
N.B. If team i's budget is such that the value taken by equation (1) would be greater than unity, the team's actual win percentage is constrained to equal unity $(100 \%$ wins).

The attendance-win relationship

The attendance relationship is based on historic data. For each team there is a quadratic relationship which reaches a maximum at some positive win percentage, but that critical value can be greater than $100 \%$.

Table 2: Estimated parameters for the sensitivity of attendance to wins for the American League

$\begin{array}{lccc}\text { Name } & \text { a } & \text { b } & \text { c } \\ \text { Anaheim Angels } & 1636393 & 2286830 & -821530 \\ \text { Baltimore Orioles } & 40217 & 9250152 & -6321152 \\ \text { Boston Red Sox } & 721947 & 5382117 & -3415917 \\ \text { Chicago White Sox } & 187050 & 3517734 & -1214034 \\ \text { Cleveland Indians } & -632951 & 10950601 & -7713601 \\ \text { Detroit Tigers } & -389802 & 7366947 & -4508447 \\ \text { Kansas City Royals } & -259625 & 4852119 & -2114319 \\ \text { Minnesota Twins } & -1539935 & 8070813 & -3347513 \\ \text { New York Yankees } & 1045703 & 5045135 & -1895735 \\ \text { Oakland Athletics } & -145096 & 5025231 & -1950831 \\ \text { Seattle Mariners } & 1543096 & 5363387 & -3090087 \\ \text { Tampa Bay Devil Rays } & 207550 & 2320631 & -523431 \\ \text { Texas Rangers } & 1319440 & 2970135 & -1499935 \\ \text { Toronto Blue Jays } & 284278 & 3094233 & -923433\end{array}$

N.B. Given the values of "a” in Table 2, it would be possible for a team to have negative attendance if the team won few games. This is ruled out by constraining attendance to be non-negative.

Given these two relationships profit equals

$$
\pi_{\mathrm{i}}=\mathrm{p}_{\mathrm{i}}\left(\mathrm{a}_{\mathrm{i}}+\mathrm{b}_{\mathrm{i}} \mathrm{w}_{\mathrm{i}}+\mathrm{c}_{\mathrm{i}} \mathrm{w}_{\mathrm{i}}^{2}\right)-\mathrm{B}_{\mathrm{i}}
$$

For this simulation we assume $\mathrm{p}_{\mathrm{i}}$ (average revenue per fan) is equal to $\$ 60$ for each team.

\section{Rules of the game}

Each team is required to choose a positive and finite budget figure. Collusion is not permitted. Based on these choices the win percentage, revenue and profit of each team will be determined. If more than one round is played, there is no connection between the decisions in one round and the decisions in any other. 
Appendix 2: An example of a budget slip used for the playing the game

Anaheim Angels

Round 1

Budget \$m:

Anaheim Angels

Round 2

Budget \$m:

Anaheim Angels

Round 3

Budget \$m:

Anaheim Angels

Round 4

Budget \$m:

Anaheim Angels

Round 5

Budget \$m: 


\section{Appendix 3: How to solve for the Nash equilibrium budgets on an Excel spreadsheet}

1. The input data required for this exercise consists of the parameters $b_{i}$ and $c_{i}$, revenue per fan $p_{i}$, which should be defined in three separate columns, say columns A, B and C.

2. Define the win percentages in column $D$ using equation (1) where the $B_{i}$ are numbers inputted in column E, which we can label "Rbudgets" and the parameter $\gamma$, defined in a free cell (for example, in a 14 team league, where the names are defined in the first row and the next 14 rows contain the team data, cell A17 could be used for the value of $\gamma$ ).

3. In column $\mathrm{F}$ input the formula for LHS of the equilibrium condition (9). This depends on the parameters $b_{i}$ (column $A$ ) and $c_{i}$ (column B), revenue per fan $\mathrm{p}_{\mathrm{i}}$ (column $\mathrm{C}$ ), the number of teams in the league $\mathrm{n}$, and the win percentages defined in column D.

4. Underneath the figures column $\mathrm{F}$ input the average value of these figures.

5. In column $\mathrm{G}$ input the difference between value for the team in column $\mathrm{F}$ and the average value for column $\mathrm{F}$.

6. From column G identify the team whose deviation from the average is largest and then adjust this team's Rbudget figure in column $\mathrm{E}$ until the deviation is zero (or close to zero).

7. Repeat step 5 as often as is necessary to reduce all of the deviations as close to zero as is required. Note that as the deviations in column $G$ approach zero the values in column $\mathrm{F}$ approach equality, thus satisfying equilibrium condition (9).

8. To derive team budgets from the Rbudget figures in column E, input in column $\mathrm{H}$ the LHS of equation (6), which depends on the win percentages in column $\mathrm{D}$, the parameters $\mathrm{b}_{\mathrm{i}}$ (column $\left.\mathrm{A}\right), \mathrm{c}_{\mathrm{i}}$ (column B), revenue per fan $\mathrm{p}_{\mathrm{i}}$ (column $\mathrm{C}$ ), the number of teams $\mathrm{n}$ and $\gamma$. The figures in column $\mathrm{H}$ are thus the Nash equilibrium budgets (Rbudgets are proportional to the Nash Equilibrium budgets, but only ensure that the marginal revenue of budget spending is equalised across all teams. For Nash equilibrium we also require that marginal revenue equals marginal cost). 


\section{Appendix 4: a list of sheets from the Excel file}

Base data: attendance and win percent data for the American League. Other variables include dummies for date of a new ballpark opened and league honours won.

Expenditure and winning: This sheet uses the minimum sum of squared deviations to estimate the value of $\gamma$ which best fits the data on wages and win percent using equation (1).

Revenue and costs AL 03: This is actual revenue and cost data for the American League in 2003

Regression Results: This sheet shows the results of the linear regressions of attendance on win percent.

Quadratic estimates: This sheet shows how the quadratic parameter estimates were derived. The method is explained in Szymanski (2004b).

Attendance and winning (chart): This shows the relationship between attendance and win percentage for some of the teams.

Model: This is sheet used to input the budget choices made by participants in the simulation.

Results: This sheet should be used to keep a record (by cutting and pasting) of each round.

$\mathbf{N E} \mathbf{g}=\mathbf{0 . 1 6}$ : This sheet gives the Nash equilibrium choices when $\gamma=0.16$, assuming profit maximisation.

$\mathbf{N E} \mathbf{g}=\mathbf{0 . 2 5}$ : This sheet gives the Nash equilibrium choices when $\gamma=0.25$, assuming profit maximisation.

$\mathbf{N E} \mathbf{g}=\mathbf{0 . 5}$ : This sheet gives the Nash equilibrium choices when $\gamma=0.5$, assuming profit maximisation.

$\mathbf{N E} \mathbf{g}=\mathbf{1}$ : This sheet gives the Nash equilibrium choices when $\gamma=1$, assuming profit maximisation.

Planner's equilibrium: This sheet gives the distribution of win percentages that maximises total attendance

Summary: This sheet summarises all the relevant variables for the different Nash equilibria and the planner's equilibrium. It also gives the budget choices when teams are win maximisers. Note that for some values of $\gamma$, there are some clubs that cannot avoid losses when all teams are win maximisers. 


\section{Appendix 5: A note on parameter values in the model}

\section{(a) the value of $\gamma$}

For the simulation a value of $\gamma$ equal to $1 / 2$ is convenient. It is possible, however, to derive a value of $\gamma$. The sheet labelled "Expenditure and winning" estimates the parameter $\gamma$ using data from the American League for the period 1988-2004. This is done by defining the expected win percentage for each team in each season based on the payrolls of all team specified in equation (1), and then varying the parameter $\gamma$ so the sum of squared deviations of expected from actual win percentage is minimised. The value of $\gamma$ that does this for the American League is 0.16 , suggesting a relatively low sensitivity. Estimates for other leagues at other times could differ significantly.

\section{(b) the value of the "a", "b" and "c" parameters}

Using the "Base data" sheet, the "regression results" shows the econometric results for the relationship between attendance at the ballpark and these factors. For each club, an increase in winning percentage increases attendance, but at each club the sensitivity varies.

The estimated relationship is linear, suggesting that, whatever, the level of win percentage, an addition to win percentage produces the same increase in attendance. More realistically, it might be expected that increases in win percentages produce a smaller and smaller addition to attendance (diminishing returns). It might even be the case that attendance decreased if win percentage rose too high, since fans would lose the element of unpredictability that makes sporting contests attractive.

This non-linearity is hard to estimate for the American League, since teams seldom achieve extreme win percentages. Out of the 363 team seasons in the database here, there were only three cases of win percentages below 33\% and only three above $66 \%$ (the highest was 71\% and the lowest 26\%). However, it is likely that if a team won more than $80 \%$ of its games it would at least start to face capacity constraints. The sheet "quadratic estimates" shows a non-linear estimate can be produced from the regression results and the assumption of a capacity constraint, and the chart “Attendance and winning” illustrates the relationship for several clubs. 


\section{References}

Atkinson, Scott, Linda Stanley and John Tschirhart. 1988. "Revenue Sharing as an incentive in an agency problem: an example from the National Football League" Rand Journal of Economics, 19, 1, 27-43

El-Hodiri, Mohamed and James Quirk. 1971. “An Economic Model of a Professional Sports League” Journal of Political Economy, 79, 1302-19

Fort, Rodney and James Quirk. 1995. "Cross Subsidization, Incentives and Outcomes in Professional Team Sports Leagues” Journal of Economic Literature, XXXIII, 3, 1265-1299

Késenne, Stefan. 1996 "League Management in Professional Team Sports with Win Maximizing Clubs”, European Journal for Sport Management, vol. 2/ 2, pp. 14-22

Késenne, Stefan. 2000. "Revenue Sharing and Competitive Balance in Professional Team Sports” Journal of Sports Economics, Vol 1, No 1, pp56-65.

Marburger, Daniel. 1997. "Gate revenue sharing and luxury taxes in professional sports" Contemporary Economic Policy, XV, April, 114-123.

Stefan Szymanski, 2003. “The Economic Design of Sporting Contests” Journal of Economic Literature, XLI, 1137- 1187.

Stefan Szymanski, 2004a, "Professional team sports are only a game: the Walrasian fixed supply conjecture model, Contest-Nash equilibrium and the Invariance Principle” Journal of Sports Economics, 5, 2, 111-126.

Stefan Szymanski, 2004b, “Tilting the Playing Field: Why a sports league planner would choose less, not more, competitive balance”, mimeo.

Stefan Szymanski and Stefan Késenne, 2004. "Competitive balance and gate revenue sharing in team sports” Journal of Industrial Economics, LII, 1, 165-177.

Vrooman, John. 1995. “A General Theory of Professional Sports Leagues” Southern Economic Journal, 61, 4, 971-90 